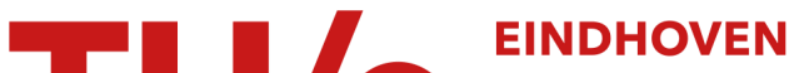 UNIVERSITY OF TECHNOLOGY
}

\section{Therapeutic potential of adipose-derived stromal cells in age- related osteoporosis}

\section{Citation for published version (APA):}

Mirsaidi, A., Genelin, K., Vetsch, J. R., Stanger, S., Theiss, F., Lindtner, R. A., von Rechenberg, B., Blauth, M., Müller, R., Kuhn, G., Hofmann, S., Ebner, H. L., \& Richards, P. J. (2014). Therapeutic potential of adiposederived stromal cells in age-related osteoporosis. Biomaterials, 35(26), 7326-7335.

https://doi.org/10.1016/j.biomaterials.2014.05.016

DOI:

10.1016/j.biomaterials.2014.05.016

Document status and date:

Published: 01/01/2014

\section{Document Version:}

Accepted manuscript including changes made at the peer-review stage

\section{Please check the document version of this publication:}

- A submitted manuscript is the version of the article upon submission and before peer-review. There can be important differences between the submitted version and the official published version of record. People interested in the research are advised to contact the author for the final version of the publication, or visit the $\mathrm{DOI}$ to the publisher's website.

- The final author version and the galley proof are versions of the publication after peer review.

- The final published version features the final layout of the paper including the volume, issue and page numbers.

Link to publication

\section{General rights}

Copyright and moral rights for the publications made accessible in the public portal are retained by the authors and/or other copyright owners and it is a condition of accessing publications that users recognise and abide by the legal requirements associated with these rights.

- Users may download and print one copy of any publication from the public portal for the purpose of private study or research.

- You may not further distribute the material or use it for any profit-making activity or commercial gain

- You may freely distribute the URL identifying the publication in the public portal.

If the publication is distributed under the terms of Article $25 \mathrm{fa}$ of the Dutch Copyright Act, indicated by the "Taverne" license above, please follow below link for the End User Agreement:

www.tue.nl/taverne

Take down policy

If you believe that this document breaches copyright please contact us at:

openaccess@tue.nl

providing details and we will investigate your claim. 


\title{
Therapeutic potential of adipose-derived stromal cells in age-related osteoporosis
}

\author{
Ali Mirsaidi a, b, 1 , Konstantin Genelin ${ }^{\text {c, } 1}$, Jolanda R. Vetsch ${ }^{\mathrm{d}}$, Scott Stanger ${ }^{\mathrm{d}}$, Felix Theiss ${ }^{\mathrm{e}}$, \\ Richard A. Lindtner ${ }^{\mathrm{C}}$, Brigitte von Rechenberg ${ }^{\mathrm{e}}$, Michael Blauth ${ }^{\mathrm{c}}$, Ralph Müller ${ }^{\mathrm{d}}$, \\ Gisela A. Kuhn ${ }^{d}$, Sandra Hofmann Boss ${ }^{d,}$, g, Hannes L. Ebner ${ }^{c}$, Peter J. Richards a, b, * \\ a Bone and Stem Cell Research Group, CABMM, University of Zurich, 8057 Zurich, Switzerland \\ ${ }^{\mathrm{b}}$ Institute of Physiology and Zurich Center for Integrative Human Physiology (ZIHP), University of Zurich, 8057 Zurich, Switzerland \\ c Department of Trauma Surgery and Sports Medicine, Innsbruck Medical University, A-6020 Innsbruck, Austria \\ d Institute for Biomechanics, ETH Zurich, 8093 Zurich, Switzerland \\ e Musculoskeletal Research Unit, CABMM, University of Zurich, 8057 Zurich, Switzerland \\ ${ }^{\mathrm{f}}$ Department of Biomedical Engineering, Eindhoven University of Technology, P.O. Box 513, 5600 MB Eindhoven, The Netherlands \\ ${ }^{\mathrm{g}}$ Institute for Complex Molecular Systems, Eindhoven University of Technology, P.O. Box 513, Eindhoven 5600 MB, The Netherlands
}

\section{A R T I C L E I N F O}

\section{Article history:}

Received 24 April 2014

Accepted 5 May 2014

Available online 2 June 2014

\section{Keywords:}

\section{Osteoporosis}

Osteogenesis

Stem cell

Bone regeneration

Transplantation

\begin{abstract}
A B S T R A C T
Adipose-derived stromal cells (ASCs) are increasingly being used for orthopedic-based tissue engineering approaches due to their ability to readily undergo osteogenic differentiation. In the present study, we used in vitro and in vivo approaches to evaluate the use of ASCs as a treatment strategy for age-related osteoporosis. Molecular, histological and micro-computed tomography (micro-CT) based approaches confirmed that ASCs isolated from 18-week-old osteoporotic senescence-accelerated mice (SAMP6) were capable of undergoing osteogenesis when cultured in either silk fibroin (SF) scaffolds or scaffold-free microtissues (ASC-MT). A single intratibial injection of CM-Dil-labeled isogeneic ASCs or ASC-MT into SAMP6 recipients significantly improved trabecular bone quality after 6 weeks in comparison to untreated contralateral bones, as determined by micro-CT. Injected ASCs could be observed in paraffin wax bone sections at $24 \mathrm{~h}$ and 6 weeks post treatment and induced a significant increase in several molecular markers of bone turnover. Furthermore, a significant improvement in the osteogenic potential of osteoporotic patient-derived human bone marrow stromal cells (BMSCs) was observed when differentiated in conditioned culture media harvested from osteoporotic patient-derived human ASCs. These findings therefore support the use of ASCs as an autologous cell-based approach for the treatment of osteoporosis.
\end{abstract}

() 2014 Elsevier Ltd. All rights reserved.

\section{Introduction}

Osteoporosis is characterized by significant deficits in both bone mass and bone quality, resulting in low bone strength and a reduced resistance to fractures [1]. There is now a mounting body of scientific evidence to suggest that impaired osteogenic differentiation of resident bone marrow stromal cells (BMSCs) may play a decisive role in mediating osteoporotic bone loss. Deficiencies in osteogenesis have previously been reported in BMSCs isolated from osteoporotic patients, where significant decreases in osteoblast-

\footnotetext{
* Corresponding author. CABMM, University of Zurich, Winterthurerstrasse 190, CH-8057 Zürich, Switzerland. Tel.: +41 44635 3801; fax: +41 446356840.

E-mail address: peter.richards@cabmm.uzh.ch (P.J. Richards).

1 Authors contributed equally.
}

mediated mineral deposition were observed [2-4]. Inadequacies in the osteogenic capacity of BMSCs have also been linked to osteoporotic bone phenotypes associated with various animal models of aging [5-9]. Furthermore, the diminished osteogenic differentiation potential of BMSCs from osteoporotic patients appears to be in direct contrast to their ability to form adipocytes, thereby introducing the concept of fat marrow accretion as a potential confounding factor in the regulation of bone quality [7,9-11]. Nevertheless, despite these observations, the most widely prescribed treatments for osteoporosis are focused on inhibiting bone resorption [12]. The fact that BMSCs represent a critical component of the homeostatic machinery controlling bone turnover [13], alternative therapeutic strategies designed at targeting the BMSC niche in osteoporotic bone marrow may therefore warrant further consideration. 
The use of adipose-derived stromal cells (ASCs) for the purpose of enhancing orthopedic tissue repair and regeneration is now widespread in areas of both experimental and clinical research $[14,15]$. ASCs have several advantages over other multipotent stem cell sources in that they are easily accessed non-invasively and have been shown to maintain both their proliferative [16-18] and osteogenic [17-19] potential with age. Moreover, we and others have recently reported that unlike their BMSC counterparts, the osteogenic differentiation capabilities of ASCs isolated from osteoporotic humans and mice remain intact $[4,20]$, thereby highlighting their potential as an autologous cell-based therapy for treating age-related bone loss. Indeed, encouraging results have already been obtained from several studies investigating the therapeutic effects of systemically and locally administered ASCs on experimental osteoporosis [21-23]. However, to date, all studies investigating the therapeutic potential of ASCs in osteoporosis have focused on the prevention of bone loss in ovariectomized (OVX) mouse models, and have utilized cells obtained from nonosteoporotic animals.

In the present study, we hypothesize that ASCs isolated from osteoporotic SAMP6 mice have the capacity to generate mineralized matrix when induced to undergo osteogenesis in threedimensional (3-D) culture systems, and can significantly enhance various parameters of bone quality in vivo following a single low dose intratibial injection. We use molecular, biochemical, histological and micro-CT analyses to evaluate the osteogenic potential of osteoporotic SAMP6-derived ASCs in 3-D scaffold-based and scaffold-free systems, and to validate their use as a therapeutic intervention for treating age-related bone loss in a mouse model for senile osteoporosis. Furthermore, we assess the capacity of ASCs to influence the osteogenic differentiation of BMSCs isolated from aged osteoporotic patients.

\section{Materials \& methods}

\subsection{Animals}

Experiments were performed using 18-week-old male and female senescence accelerated mouse prone 6 (SAMP6) mice (Institute for Laboratory Animal Science, University of Zurich, Switzerland). All animal research procedures were approved by the Animal Experimentation Committee of the Veterinary Office of the Canton of Zurich, Switzerland and followed the guidelines of the Swiss Federal Veterinary Office for the use and care of laboratory animals.

\subsection{Human patients}

Human ASCs and BMSCs were harvested from a total of $n=6$ non-osteoporotic and $n=9$ osteoporotic female donors ( $>65$ years of age) undergoing routine surgery. Osteoporosis was confirmed by dual energy X-ray absorptiometry (DXA; Hologic QDR 4500) according to WHO guidelines. All procedures were carried out in accordance with the ethics commission guidelines for Innsbruck Medical University.

\subsection{Cell isolation and culture}

ASCs isolated from inguinal fat pads of 18-week-old male SAMP6 mice were purified and characterized according to previously published protocols established in our laboratory $[20,24]$. Human BMSCs or ASCs were harvested from the femoral medullary cavity or subcutaneous adipose tissue respectively, as previously described $[20,24,25]$. In all cases, cells were maintained in normal growth medium consisting of Dulbecco's modified eagle medium (DMEM-low glucose, with Glutamax; Life Technologies, Zug, Switzerland), supplemented with $10 \%$ fetal bovine serum (FBS; Life Technologies) and penicillin (50 units $/ \mathrm{ml}$ ) and streptomycin (50 $\mu \mathrm{g} / \mathrm{ml}$ ) (Life Technologies). Cells were used between passage 2 and 4 unless otherwise stated.

\subsection{Osteogenesis of SAMP6-derived ASCs in 3-D culture systems}

The osteogenic induction of mouse ASCs was performed using protocols previously established in our laboratory $[20,24]$. ASC-seeded SF scaffolds were prepared as previously described [26,27]. Briefly, silk cocoons from Bombyx Mori L. were cooked twice in sodium carbonate for $1 \mathrm{~h}$ to extract sericins. Dried silk was dissolved in 9M lithium bromide and dialyzed against ultrapure water for 36 h. Frozen, dialyzed silk solution was lyophilized for four days and dissolved in hexafluoroisopropanol (HFIP) at $17 \%(\mathrm{w} / \mathrm{v})$. Silk solution $(1 \mathrm{ml})$ was pipetted onto $2.5 \mathrm{~g}$ sodium chloride granules of 300-400 $\mu$ m diameter and left for 3 days until the HFIP had completely evaporated. Sodium chloride was leached out for $24 \mathrm{~h}$ in water and scaffolds cut into discs of $5 \mathrm{~mm}$ in diameter and $2 \mathrm{~mm}$ in height. For cell cultivation on SF scaffolds, $3 \times 10^{6}$ ASCs per scaffold were seeded by pipetting a droplet of $50 \mu \mathrm{l}$ of cell suspension on top of each scaffold. Constructs were placed in an incubator at $37{ }^{\circ} \mathrm{C}, 5 \% \mathrm{CO}_{2}, 100 \%$ humidity for $90 \mathrm{~min}$ and a drop of culture medium was applied every 20 min to prevent scaffolds from drying out. Five cell seeded constructs were fixed on the bottom of a bioreactor applicable for micro-CT monitoring. Each bioreactor was filled with $5 \mathrm{ml}$ of osteogenic induction medium consisting of normal growth medium supplemented with $50 \mu \mathrm{m}$ L-ascorbic acid 2-phosphate sesquimagnesium salt hydrate (Sigma-Aldrich, Buchs, Switzerland), $10 \mathrm{~mm} \beta$-glycerophosphate (Sigma-Aldrich) and $5 \mu \mathrm{m}$ retinoic acid (Sigma-Aldrich). Medium was exchanged three times per week for up to 6 weeks. ASC-MT cultures were prepared as previously described $[24,28]$. Briefly, $2.5 \times 10^{3}$ ASCs were cultured in $25 \mu \mathrm{l}$ hanging drops of osteogenic medium in Terasaki plates (VWR, Switzerland) for up to 6 days. In all cases, osteogenic differentiation was evaluated by Alizarin red (Sigma-Aldrich) staining of paraffin wax tissue sections and by the analysis of osteogenic gene expression using quantitative reverse-transcription polymerase chain reaction (qRT-PCR). Fully formed ASC-MT were also cultured in sterile plastic culture plates under normal growth conditions or in osteogenic medium for up to 14 days, and the ability of ASCs to migrate out from the microtissues and also induce mineralization determined by microscopic analysis.

\subsection{Osteogenesis of human BMSCs from osteoporotic patients}

Age-matched BMSCs harvested from osteoporotic (OP; $n=9$ ) or nonosteoporotic (non-OP; $n=6$ ) patients were cultured for up to 21 days in osteogenic medium (OM) consisting of $50 \mu \mathrm{M}$ L-ascorbic acid 2-phosphate sesquimagnesium salt hydrate, $10 \mathrm{~mm} \beta$-glycerophosphate and $10 \mathrm{~nm}$ dexamethasone (Sigma-Aldrich), and osteogenesis compared at selected time points using the alkaline phosphatase (ALP) activity assay or by Alizarin red staining as previously described [25]. For studies investigating the influence of osteoporotic patientderived ASCs on the osteogenic potential of osteoporotic patient-derived BMSCs, cultures of human BMSCs $(n=4)$ or ASCs $(n=4)$ isolated from age-matched osteoporotic patients were initially used to generate conditioned medium. Supernatants from cells cultured in normal growth medium (GM) were harvested at $48 \mathrm{~h}$ to generate conditioned medium (CM) designated ASC-CM or BMSC-CM. For osteogenic differentiation, human osteoporotic patient-derived BMSCs $(n=4)$ were
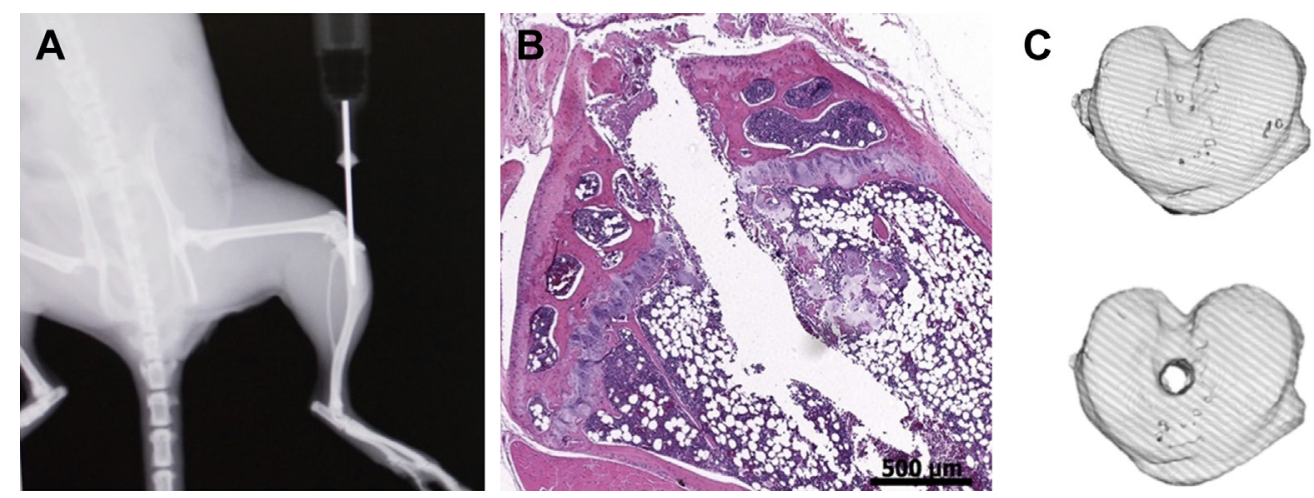

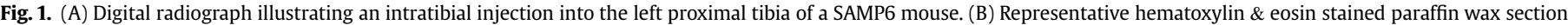

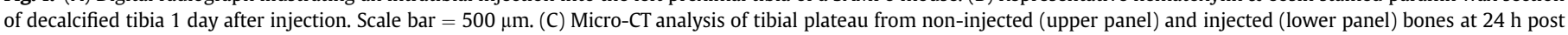
treatment. 
Table 1

List of TaqMan Gene Expression Assays used in RT-PCR analysis.

\begin{tabular}{lll}
\hline Gene symbol & Protein product & Assay ID \\
\hline Alpl & Alkaline phosphatase & Mm01187117_m1 \\
Col1a2 & Collagen type 1A 2 & Mm00483888_m1 \\
Ctsk & Cathepsin K & Mm00484039_m1 \\
Gapdh & Glyceraldehyde-3-phosphate dehydrogenase & Mm99999915_g1 \\
HtrA1 & High temperature requirement protease A1 & Mm00479887_m1 \\
Ibsp & Integrin binding sialoprotein & Mm00492555_m1 \\
Mrps12 & Mitochondrial ribosomal protein S12 & Mm00488728_m1 \\
Opn & Osteopontin & Mm01611440_m1 \\
Tnfa & Tumor necrosis factor alpha & Mm00443258_m1 \\
\hline
\end{tabular}

a TaqMan Expression Assay identity code according to supplier (Life Technologies, Zug, Switzerland).

cultured for up to 14 days in OM supplemented with $100 \%$ of either ASC-CM or BMSC-CM in triplicates, and osteoblast formation determined by Alizarin red staining as previously described [25].

\subsection{Intratibial injection}

SAMP6 mice were anaesthetized with an i.p. injection of Fentanyl $(0.05 \mathrm{mg} / \mathrm{kg})$, Midazolam ( $5 \mathrm{mg} / \mathrm{kg}$ ) and Medetomidin $(0.5 \mathrm{mg} / \mathrm{kg})$ in $0.9 \% \mathrm{NaCl}$, and the left tibia injected with either undifferentiated ASCs $(n=9)$, ASCs pre-differentiated for 3 days in osteogenic medium either as a monolayer $(n=13)$ or as ASC-MT $(n=13)$, or PBS/ EDTA (vehicle; $n=9$ ). Prior to implantation, cells were labeled with CM-Dil (Life Technologies) according to the manufacturer's recommendations. A pre-drilled hole was created in the left proximal tibia of 18-week-old female SAMP6 mice using a 26gauge needle. Following brief flushing of the cavity with heparin (10 IE/ml), $10 \mu \mathrm{l}$ of cells $\left(15 \times 10^{4}\right)$ or vehicle were injected directly into the medullary canal using a Hamilton syringe (Fig. $1 \mathrm{~A}-\mathrm{C}$ ). The contralateral tibia remained untreated and served as the control. Tracking of injected CM-Dil-labeled ASCs was performed in dewaxed DAPI-stained paraffin sections of tibia taken at $24 \mathrm{~h}$ and 42 days following injection and analyzed using the Leica DMI6000B automated inverted research microscope system (Leica Microsystems, Heerbrugg, Switzerland).

\subsection{Micro-CT monitoring of SF scaffolds}

Bioreactors containing cell seeded scaffolds ( $n=5$ per bioreactor) were scanned weekly for up to 6 weeks on a micro-CT40 (Scanco Medical AG, Brüttisellen,
Switzerland). Scans were operated at 45kVp energy level, $177 \mu \mathrm{A}$ intensity, $200 \mathrm{~ms}$ integration time, 2 -fold frame-averaging at high resolution mode leading to an isotropic resolution of $18 \mu \mathrm{m}$. The bioreactors were removed from the incubator for $1 \mathrm{~h}$ during the measurement. Greyscale images were filtered by applying a 3-D Gaussian filter (sigma 1.2, support 1) and a global threshold of $12.8 \%$ of the maximal grey values (corresponding to a density value of $127.59 \mathrm{mg} \mathrm{HA} / \mathrm{cm}^{3}$ ). Unconnected objects smaller than 50 voxels were not analyzed. Samples were evaluated morphometrically for mineralized tissue volume density (BV/TV).

\subsection{Micro-CT analysis of mouse tibia}

Tibia were excised and stored in 70\% ethanol. Micro-CT40 (Scanco Medical AG, Brüttisellen, Switzerland) scans were performed with the X-ray tube operating at an energy of $55 \mathrm{kVp}$ and an intensity of $145 \mu \mathrm{A}$. Three-dimensional images with an isotropic voxel size of $15 \mu \mathrm{m}$ were reconstructed from 1000 projection images taken over $180^{\circ}$ and an integration time of $300 \mathrm{~ms}$. A 3-D Gaussian filter (sigma 0.8 support 1) was then applied to all images, and a global threshold corresponding to $22.4 \%$ of the maximum grey values was used to separate bone from marrow and surrounding soft tissues. Three compartments were selected for the evaluation. Full bone and cortical bone ( $5 \%$ of bone length located at $50 \%$ of length) were determined by an automated algorithm [29]. A trabecular compartment of 150 slices located distal of the growth plate was selected by manual contouring. Bone morphometric parameters were calculated within each compartment as described previously $[30,31]$.

\section{9. $q R T-P C R$ analysis}

Total RNA was purified from either mouse ASCs or mouse bone tissue using TRIzol reagent and treated with TURBO DNase (Life Technologies) as previously described $[20,28]$. RNA $(0.5 \mu \mathrm{g})$ was reverse transcribed to cDNA using superscript II (Life Technologies) and random hexanucleotide primers (Promega AG, Dübendorf, Switzerland), and quantification of mRNA expression performed using TaqMan Gene Expression Assays (Life Technologies) (Table 1). For all in vitro studies, values were normalized to Mrps12 mRNA levels and presented as fold change according to the $2^{-\Delta \Delta C T}$ method unless otherwise stated. For the measurement of gene expression levels in bone tissue, total RNA was harvested from the diaphysis of 5-6 bone samples and values normalized to Gapdh mRNA levels and presented as $2^{-\Delta C T}$. Each $10 \mu \mathrm{l}$ reaction consisted of 1x TaqMan Fast Universal PCR Master Mix (Life Technologies), 1x TaqMan Gene Expression Assay and 10 ng cDNA (based upon initial RNA concentrations). All reactions were performed in triplicate in fast optical 96well reaction plates (Life Technologies) at $95{ }^{\circ} \mathrm{C}$ for $20 \mathrm{~s}$ and 40 cycles of $95{ }^{\circ} \mathrm{C}$ for $1 \mathrm{~s}$ and $60{ }^{\circ} \mathrm{C}$ for $20 \mathrm{~s}$.

A

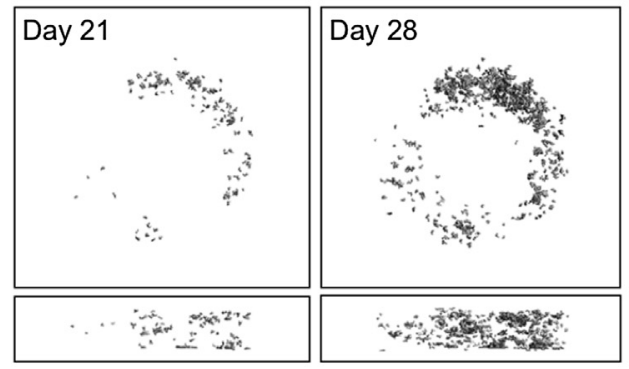

B

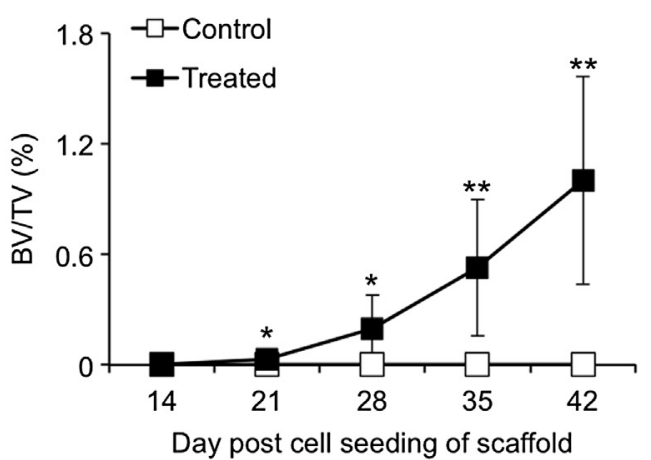

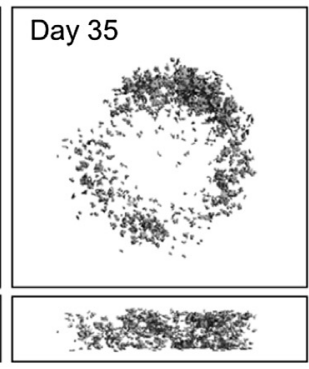

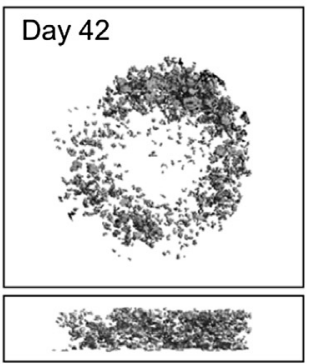

C

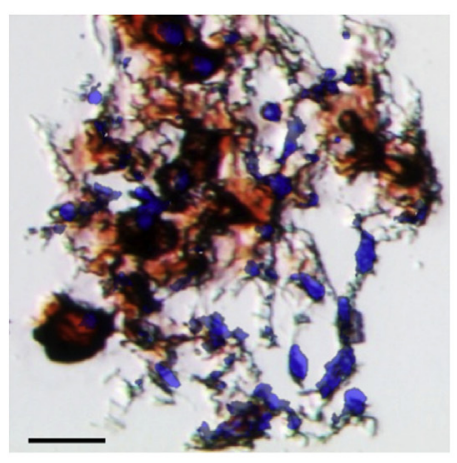

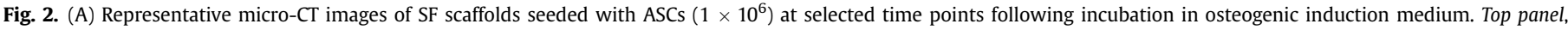

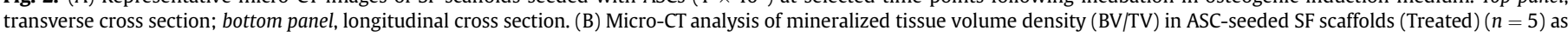

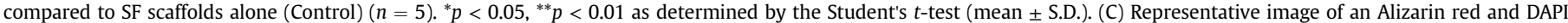

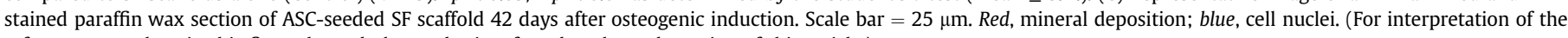
references to colour in this figure legend, the reader is referred to the web version of this article.) 


\subsection{Histology}

Paraffin wax sections of ASC microtissue spheroids were incubated with polyclonal rabbit anti-HTRA1 (1:50) or rabbit anti-osteocalcin (1:1000) using the conditions previously described [27]. Samples were then washed and incubated with goat anti-rabbit-Cy3 (1:400) for $1 \mathrm{~h}$ and mounted in DAPI containing Mowiol solution and images captured using the Leica DMI6000B system.

\subsection{Statistical analysis}

All statistical analyses were carried out using SPSS19.0 (SPSS Inc., Chicago, IL). Parametric analysis of normally distributed data was performed using either the two-tailed unpaired or paired Student's $t$-test for comparison of two groups or oneway analysis of variance (ANOVA) with Tukey's post hoc test for multiple group comparisons. In all cases, a $p$-value of $<0.05$ was considered statistically significant, and all data were expressed as mean \pm standard deviation (S.D).

\section{Results}

\subsection{Osteogenic differentiation of ASCs in 3-D culture systems}

The ability of ASCs to grow and differentiate under 3-D culture conditions was initially evaluated using SF scaffolds. Micro-CT analysis revealed significant increases in mineralized tissue formation in SF scaffolds seeded with ASCs after 21 days $(p<0.05)$, and this continued to increase up until completion of the study at day $42(p<0.01)$ (Fig. 2A and B). Alizarin red staining of paraffin sections at day 42 confirmed localization of seeded ASCs in areas of mineralized matrix (Fig. 2C). Further analysis of ASC osteogenesis was also performed using ASC-MT. ASCs readily formed spheroid microtissues when cultured in hanging drops (Fig. 3A and B). Under osteogenic conditions, ASC-MT produced mineralized matrix within 6 days (Fig. $3 \mathrm{C}$ and D) and stained positive for known markers of osteogenic differentiation including HTRA1 (Fig. 3E and F) and osteocalcin (Fig. 3G and H). Furthermore, several genetic markers of osteogenesis including alkaline phosphatase $(A l p l)(p<0.01)$, osteopontin (Opn) $(p<0.01)$, and high temperature requirement serine protease A1 (HtrA1) $(p<0.01)$ were significantly upregulated in comparison to undifferentiated ASC-MT after 3 days in culture (Fig. 3I). Additional studies revealed that ASCs initially grown as ASC-MT retained both their proliferative capacity as well as their potential to undergo osteogenesis when transferred to tissue culture plates (Fig. 4). Cells were observed to migrate out from the microtissues and could induce mineral formation within the 2-D culture system already after 7 days.

\subsection{Tracking of injected ASCS}

CM-Dil positive ASCs were easily identified within the bone marrow of mice $24 \mathrm{~h}$ following a single intratibial injection of either undifferentiated ASCs (Fig. 5A) or pre-differentiated ASC-MT
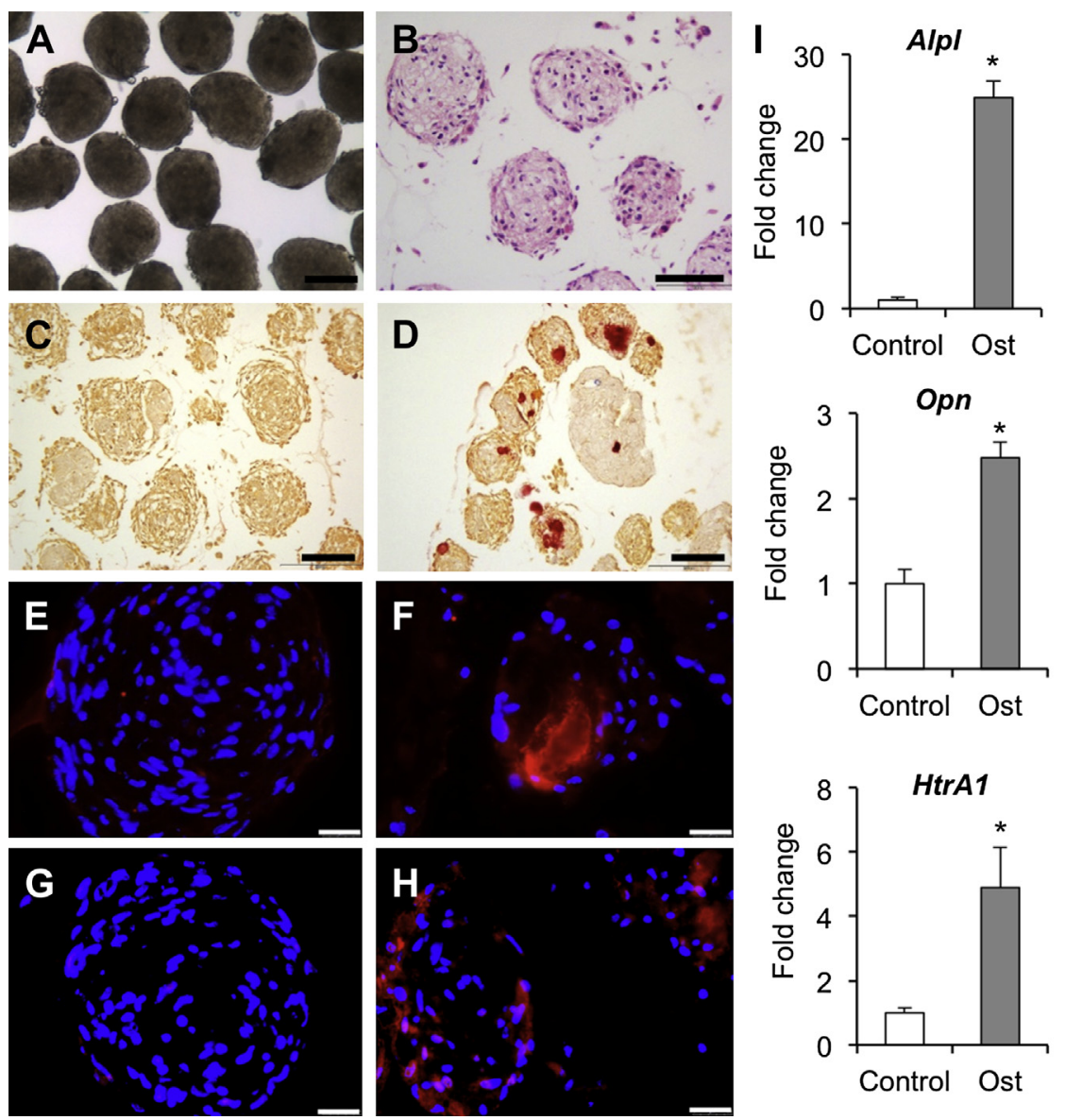

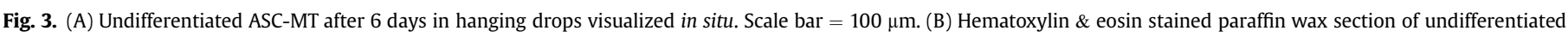

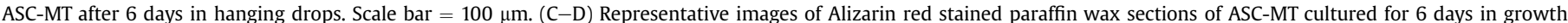

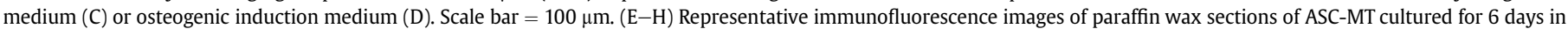

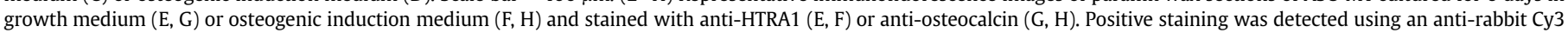

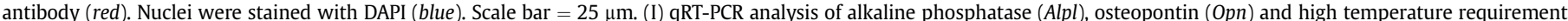

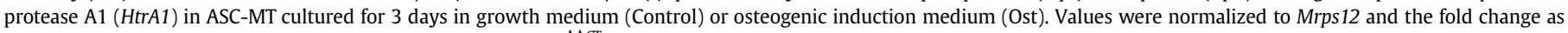
compared to undifferentiated controls determined using the $2^{-\Delta \Delta C T}$ method (mean \pm S.D.). ${ }^{*} p<0.01$ as determined by the Student's $t$-test. 

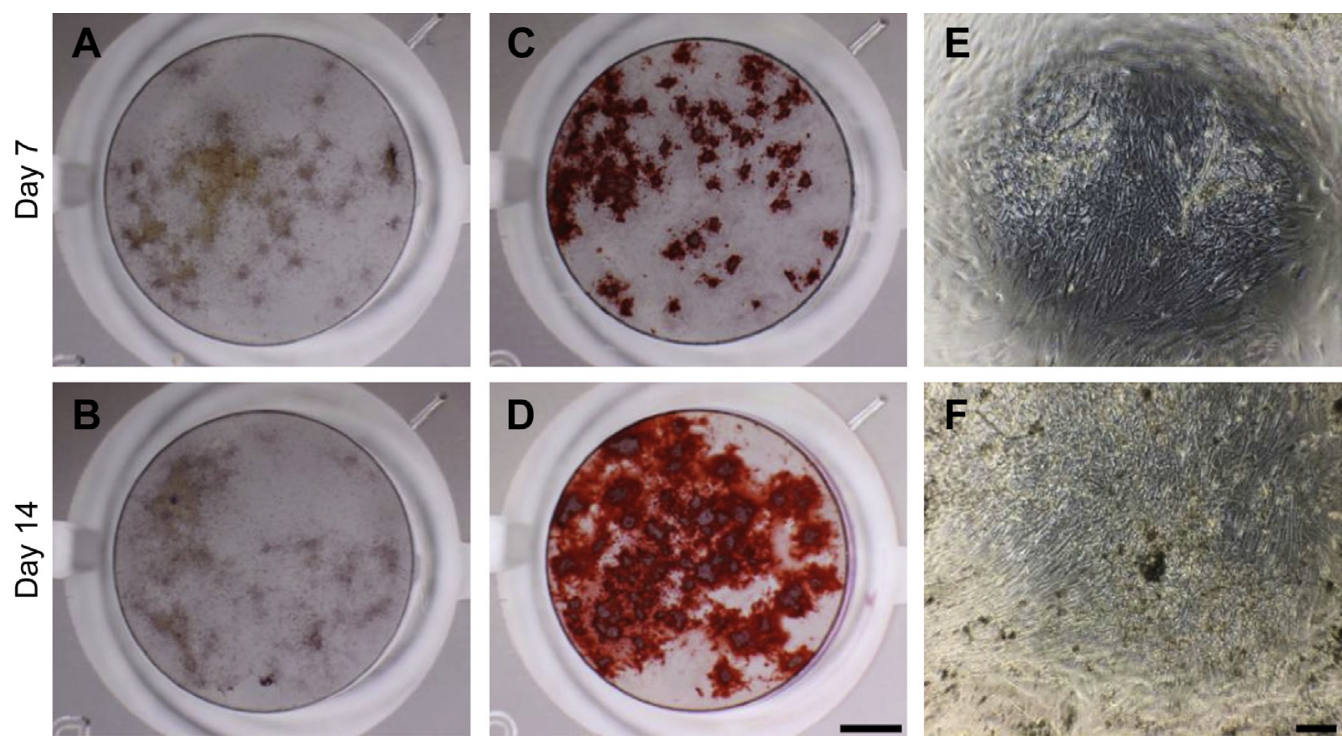

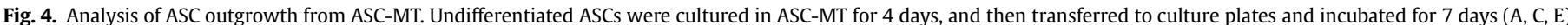

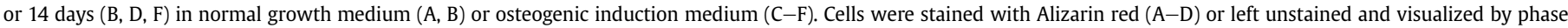
contrast light microscopy $(E-F) . A-D$, scale bar $=2 \mathrm{~mm} ; E-F$, scale bar $=500 \mu \mathrm{m}$.

(Fig. 5B). At 42 days post injection, CM-Dil positive cells were still evident within all of the treated bones, although to a much lesser extent than bone sections at $24 \mathrm{~h}$ post injection (Fig. 5C and D). Untreated contralateral bones remained absent of CM-Dil-labeled cells at all time points.

\subsection{Influence of ASCS on bone quality in SAMP6 mice}

In order to determine the effects of ASCs on bone quality, microCT was performed on bone samples taken at day 42 following treatment. Animals injected with undifferentiated ASCs, pre- differentiated ASC-MT or PBS/EDTA showed no adverse reactions and treatments were generally well tolerated. However, intratibial injections of ASCs that had been pre-differentiated as monolayers for 3 days prior to implantation resulted in $>50 \%$ mortality, with death occurring immediately after the administration of these cells. As such, we were unable to accurately assess the influence of these cells on bone quality in SAMP6 mice. Histological analysis revealed that the most likely cause of death was due to pulmonary embolism as evidenced by both cartilaginous and fibrous deposits within lung vacuoles taken from mice that died shortly after receiving an intratibial injection of pre-differentiated mouse ASCs (Suppl. Fig. 1).
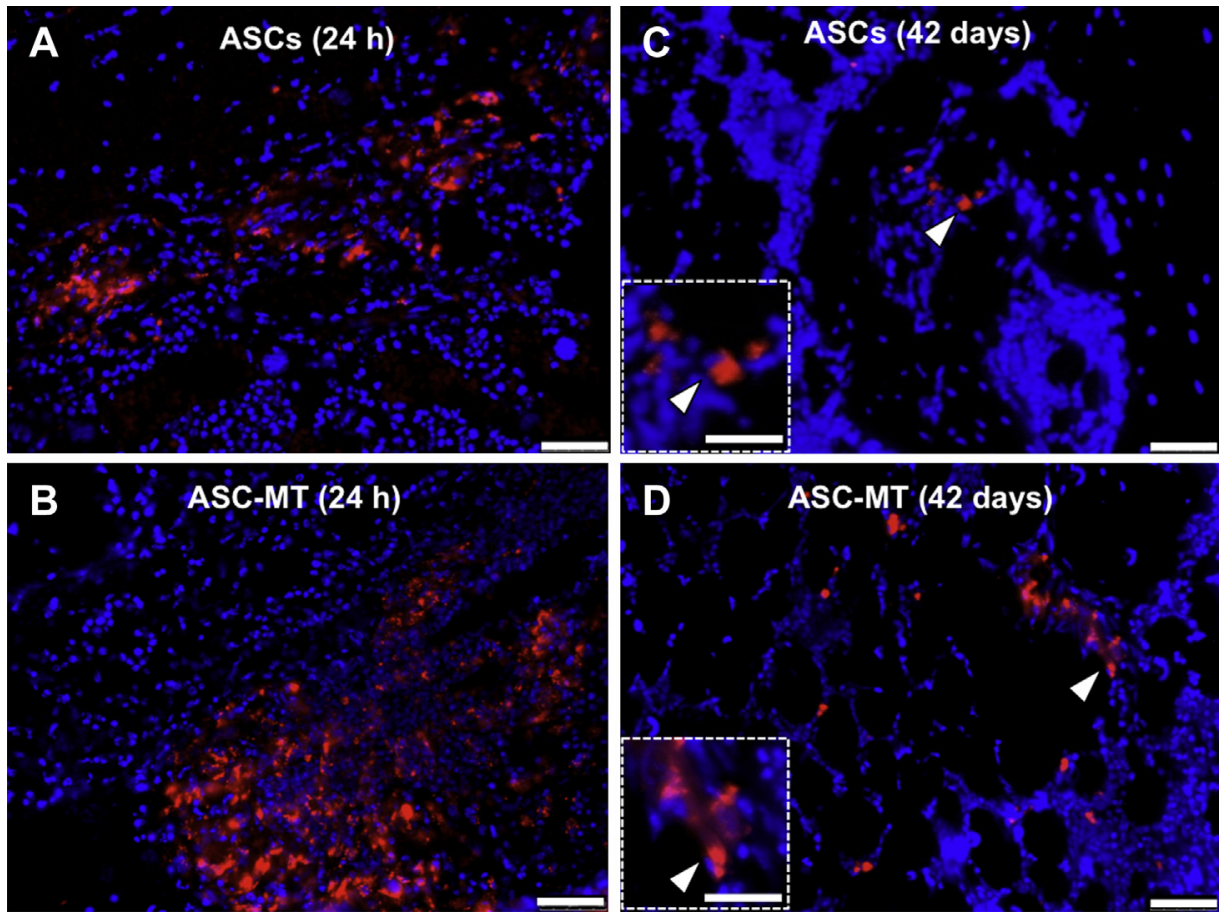

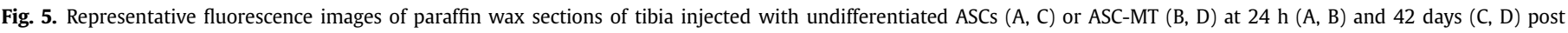
treatment. Scale bar $=50 \mu \mathrm{m}$. Inset and arrowhead, high magnification images of CM-Dil labeled cells. Scale bar $=25 \mu \mathrm{m}$. Red, CM-Dil; blue, DAPI. 
When compared to untreated contralateral tibia, undifferentiated ASC-treated and pre-differentiated ASC-MT-treated tibia demonstrated significant increases in trabecular bone volume density (BV/TV) (ASC, $p=0.01$; ASC-MT, $p=0.002$ ) and trabecular number (Tb.N) (ASC, $p=0.01$; ASC-MT, $p=0.01$ ), although trabecular thickness (Tb.Th) (ASC, $p=0.3$; ASC-MT, $p=0.1$ ), was not significantly affected (Fig. 6A and B). Furthermore, the distance between trabeculae (Tb.Sp) was significantly reduced in both treatment groups (ASC, $p=0.01$; ASC-MT, $p=0.02$ ). By contrast, no significant changes in BV/TV $(p=0.07)$, Tb.N $(p=0.89)$, Tb.Sp $(p=0.77)$ or Tb.Th $(p=0.30)$, were observed in tibia treated with PBS/EDTA when compared to the respective untreated contralateral tibia. Additionally, no significant changes in cortical bone parameters were observed in any of the treatment groups tested (data not shown).

\subsection{Effect of ASCS on gene expression in vivo}

RNA was harvested from the tibia of mice after 14 days following treatment with either PBS/EDTA or ASCs, and analyzed for various genetic markers using qRT-PCR. The expression levels of all genetic markers analyzed were found to be significantly upregulated in ASC-treated bones as compare to untreated contralateral controls (Fig. 7). Similarly, with the exception of Tnfa, PBS/EDTA treatment also induced significant increases in the expression levels of all gene markers. However, in comparison to PBS/EDTA-treated bones, ASC-treated bones showed significant increases in genetic markers associated with osteogenesis, including, Opn ( $p<0.01)$, Ibsp $(p<0.05)$, Col1a2 $(p<0.01)$, HtrA1 $(p<0.01)$, as well as resorptionassociated markers, Tnfa $(p<0.01)$ and Ctsk $(p<0.01)$. No significant differences in the expression profiles of any of the genes tested were observed between the untreated contralateral control bones of PBS/EDTA- and ASC-treated mice.

\subsection{Osteogenic differentiation of human osteoporotic BMSCS}

The osteogenic potential of human BMSCs isolated from aged osteoporotic patients was confirmed as being impaired as demonstrated by marked reductions in both ALP activity (Fig. 8A) and Alizarin red staining (Fig. 8B) in comparison to BMSCs from non-osteoporotic patients. Supplementation of osteogenic medium (OM) with conditioned medium harvested from osteoporotic patient-derived ASCs (ASC-CM) cultured under normal growth conditions, significantly enhanced mineral formation of osteoporotic patient-derived BMSCs after 14 days as compared to cells cultured in OM alone, or OM supplemented with conditioned medium from osteoporotic patient-derived BMSCs (BMSC-CM) (Fig. 8C).

\section{Discussion}

ASCs represent an easily accessible population of multipotent stromal cells, and unlike their BMSC counterparts, have the potential to readily undergo osteogenic differentiation independently of donor age and status of bone quality [18-20]. As such, the use of ASCs in bone tissue engineering is becoming more commonplace [32-37] and investigators have now started to recognize their potential as a therapeutic strategy for the treatment of osteoporosis [21-23]. Indeed, previous findings from our own studies have demonstrated that ASCs isolated from osteoporotic SAMP6 mice
A

BV/TV

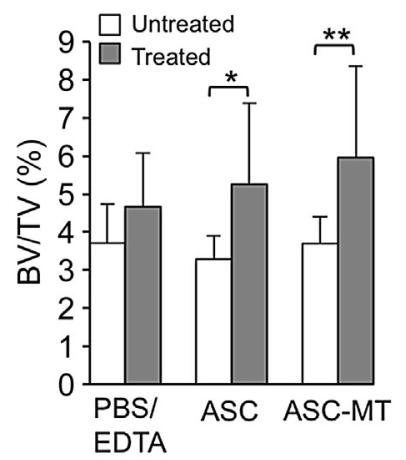

B

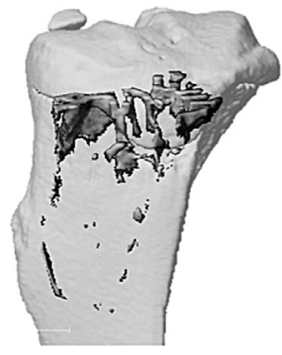

Untreated
Tb.N
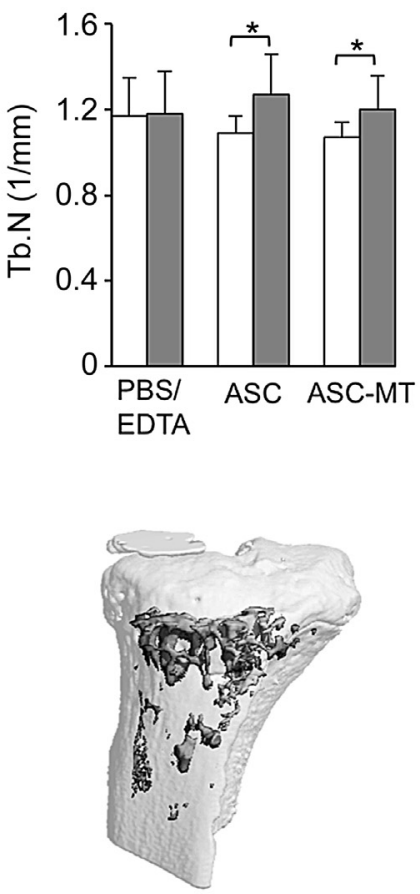

PBS/EDTA
Tb.Sp
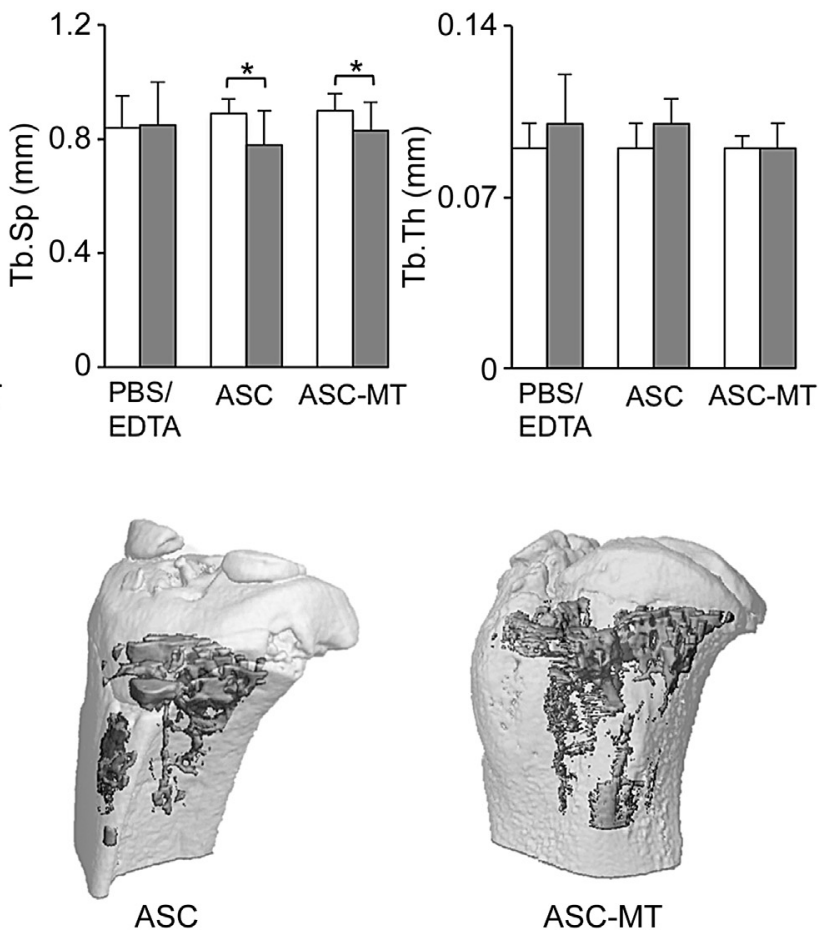

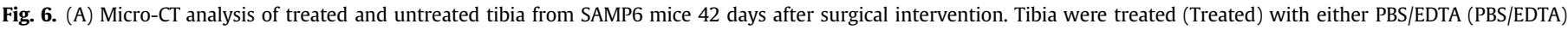

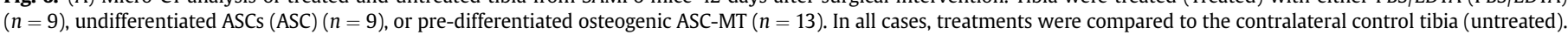

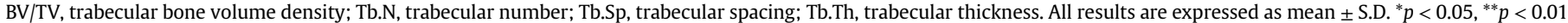

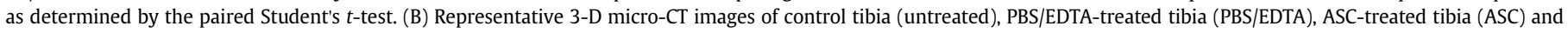
ASC-MT-treated tibia (ASC-MT). 

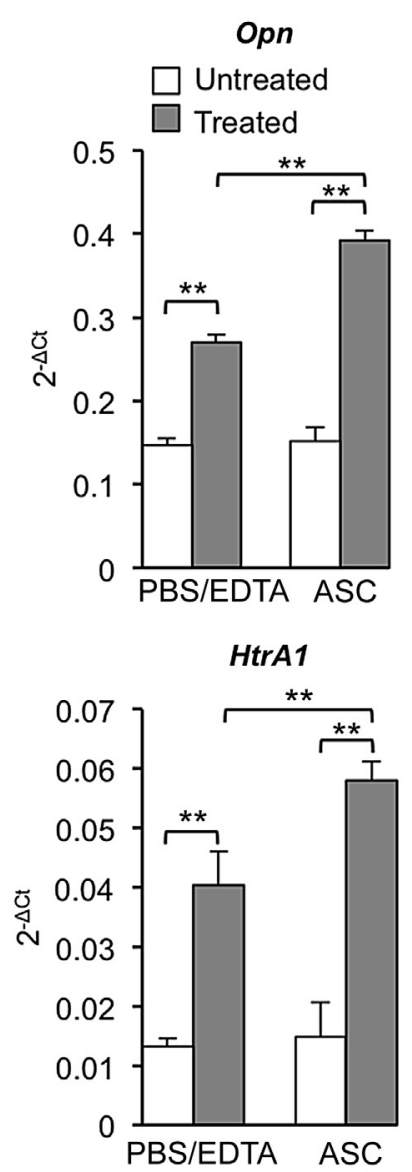

Ibsp

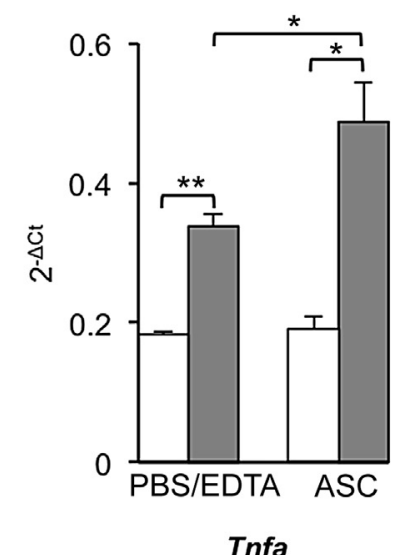

Tnfa

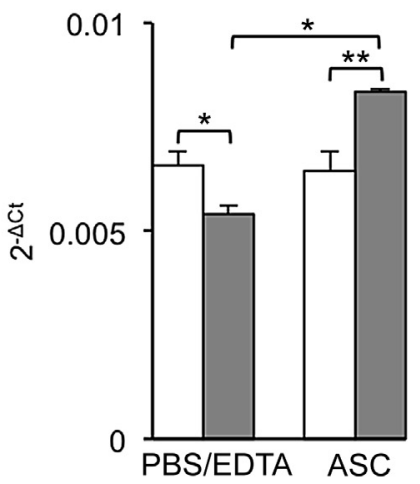

Col1a2
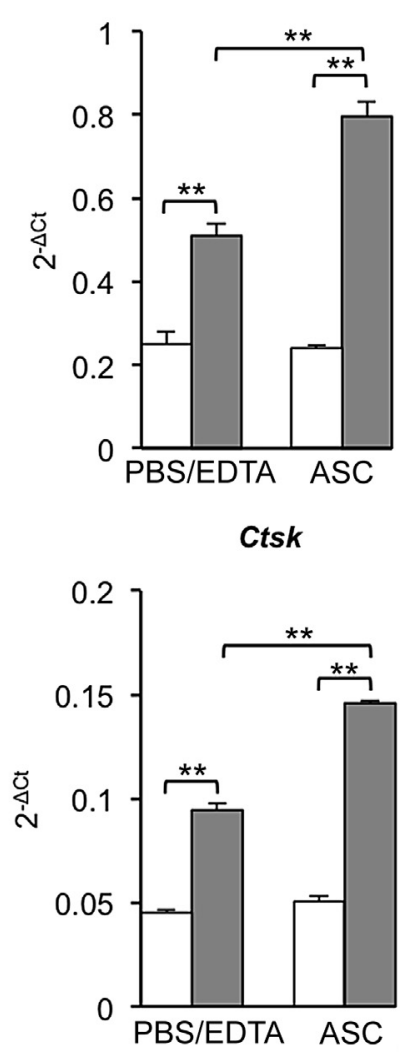

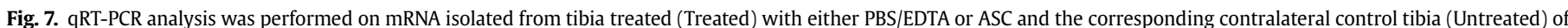

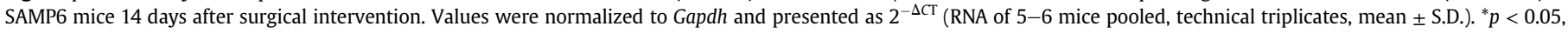

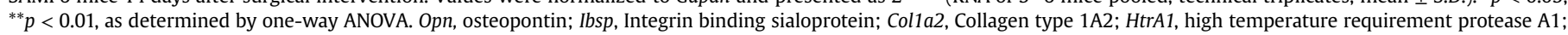
Tnfa, tumor necrosis factor alpha; Ctsk, Cathepsin k.

were able to retain their osteogenic potential under 2-D culture conditions when compared to ASCs from non-osteoporotic SAMR1 control mice [20]. However, no studies have yet sought to evaluate the therapeutic potential of isogeneic ASCs on bone quality in this mouse model for senile osteoporosis.

In the present report, in vitro 3-D culture systems were initially used to evaluate the osteogenic potential of SAMP6-derived ASCs in order to simulate a more accurate natural physiological environment. Preliminary investigations were carried out using a scaffoldbased approach, whereby micro-CT was used to monitor the mineral formation in long-term cultures of SAMP6-derived ASCs seeded on SF scaffolds. A gradual increase in mineralized tissue formation was observed in ASC-seeded scaffolds over the 42 day culture period. Additional histological analysis using Alizarin red and DAPI staining confirmed that cells could still be identified within the scaffolds after 42 days, being localized to areas of mineral deposition. Short-term osteogenic differentiation of ASCs grown in scaffold-free microtissue spheroids was observed after only 3 days in osteogenic induction medium as evidenced by significant increases in osteogenic markers Alpl, Opn and HtrA1. By day 6 , mineral deposition was apparent in the majority of tissues, along with the expression of osteogenic proteins HTRA1 and osteocalcin. Furthermore, cells cultured within spheroid microtissues were confirmed as being able to retain their proliferative capacity as well as their osteogenic potential following outgrowth onto a plastic surface. These preliminary findings therefore confirmed that SAMP6-derived ASCs were capable of maintaining their functional capacity for osteogenesis when cultured in 3-D environments and thus encouraged us to further investigate their capacity to influence bone formation in vivo.

The underlying premise for using ASCs to treat osteoporotic bone, stems from the concept that resident BMSCs are defective in terms of their ability to maintain a normal osteogenic potential and thus have a reduced tendency to generate bone-forming osteoblasts [2,3,7-9]. Supplementation of osteoporotic bone with competent osteoprogenitor cells may therefore represent a viable means by which to re-establish normal bone homeostasis and enhance bone quality. Indeed, this concept has already been tested by several independent research groups and has been shown to have significant benefits in terms of preventing bone loss in various experimental OVX mouse models. Human ASCs demonstrated a protective effect on OVX-induced bone loss in nude mice when intravenously injected at the time of surgical intervention [21]. These effects were hypothesized as being mediated mainly through paracrine effects of the transplanted ASCs based on the fact that no cells could be visualized within bone after $48 \mathrm{~h}$ post injection. Similarly, the systemic administration of genetically modified mouse ASCs restored normal bone parameters in immunocompetent mice after 28 days, although no data was presented to indicate whether ASCs could be detected within the bones of treated animals [22]. More recently, it was demonstrated that a single intratibial injection of ASCs into the femur of OVX SAMP8 mice, an aging animal model primarily used in studies of learning and memory, resulted in significant increases in bone mineral density as 


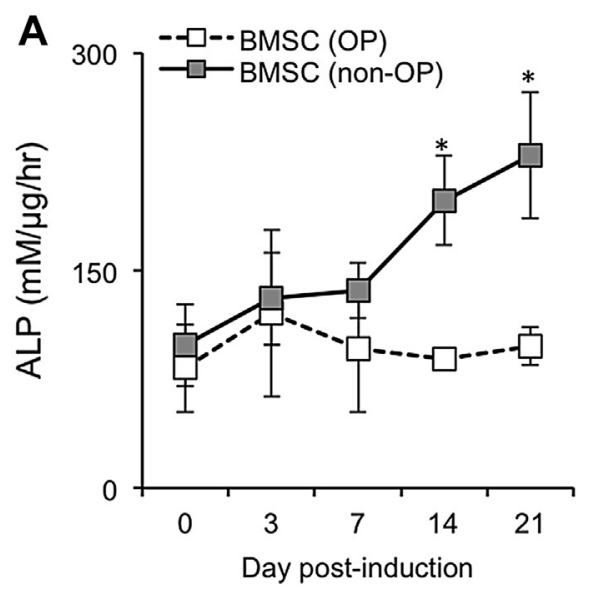

B
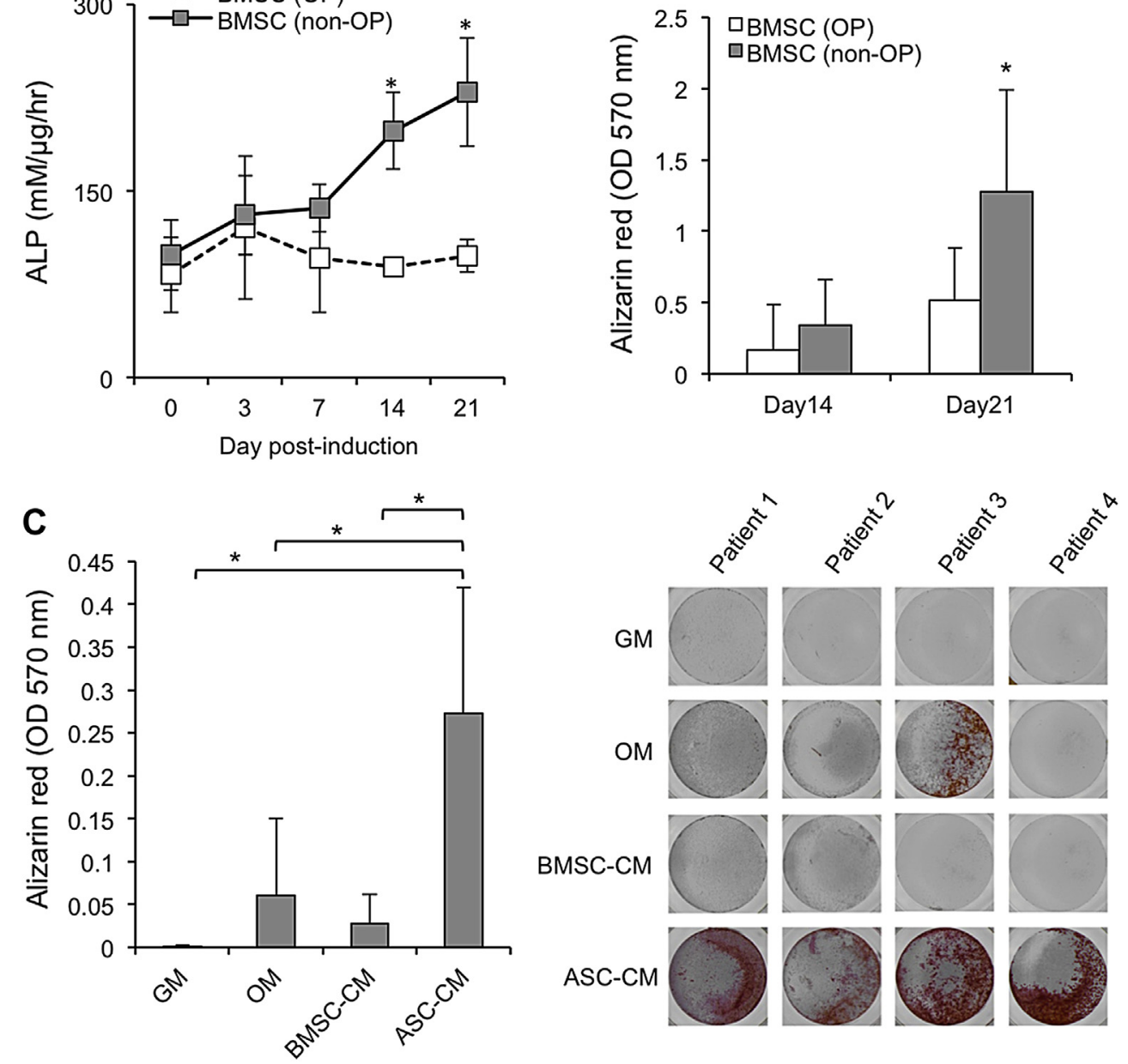

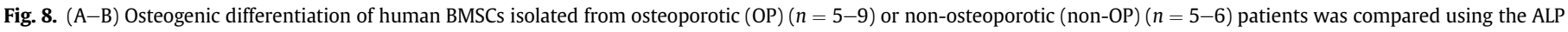

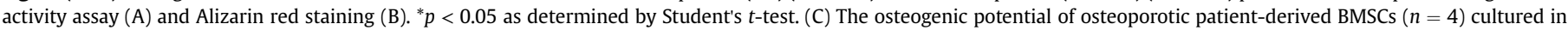

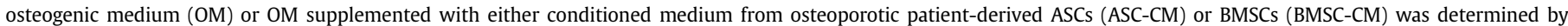

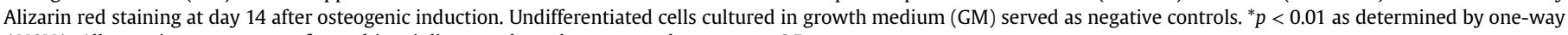
ANOVA. All experiments were performed in triplicate and results expressed as mean \pm S.D.

compared to control groups, which was evident at 4 months following the initial treatment [23]. However, these effects appeared to require the in vitro osteogenic differentiation of ASCs prior to implantation. In the present study, we observed a significant improvement in the trabecular bone quality of SAMP6 mice 42 days following a single intratibial injection of either undifferentiated SAMP6-derived ASCs or pre-differentiated osteogenic ASC-MT as compared to untreated contralateral bones. Furthermore, CM-Dil labeled cells could still be detected within the bone marrow of treated tibia even at this late time point. Attempts were also made to assess the effects of a single intratibial injection of a cell suspension of pre-differentiated osteogenic ASCs, but unexpectedly, this resulted in high mortality rates associated with pulmonary embolism. It remains unclear as to why such adverse events should have occurred following the use of these cells, especially as other studies using pre-differentiated mouse ASCs reported no untoward effects [23]. However, one possible explanation may relate to the size of cells that were injected into the bone cavity. A recent study evaluating the therapeutic potential of human placenta-derived mesenchymal stem cells (hMSCs) in ischemic stroke, demonstrated high incidences of embolism and neurological abnormalities following the intra-carotid injection of hMSCs previously cultured as monolayers [38]. By contrast, the injection of hMSC suspensions derived from 3-D microtissue spheroids, led to a subsequent improvement in neurological function with no reports of vascular obstruction. These opposing effects were attributed to differences in the size of hMSCs produced, with microtissuederived hMSCs showing a noticeable decrease in diameter as compared to hMSCs grown as monolayers. Such alterations in cell dimension may therefore go someway to explaining why osteogenic ASCs cultured as monolayers, but not as ASC-MT, resulted in embolism. Certainly, this could represent an important point of concern when considering such an approach in humans and may therefore warrant further investigation. It would appear therefore that incorporation of ASCs into microtissue spheroids may represent one possible means by which to overcome this potentially detrimental effect of pre-differentiated osteogenic ASCs when injected directly into the bone marrow cavity.

In addition to improvements being made in trabecular bone, we also observed significant increases in the gene expression of bone turnover markers in the tibia of ASC-treated mice as compared to PBS/EDTA-treated mice. This is in line with previous investigations in which the beneficial effects of locally administered ASCs on mouse bone quality have been associated with alterations in genetic markers of osteogenesis [23]. However, it should be mentioned that in the current study, the majority of genes tested 
were significantly upregulated in both ASC- and PBS/EDTA-treated mice when compared to untreated contralateral bones, thus indicating that the mere act of injecting into the tibia alone was sufficient to upregulate gene expression.

It is interesting to note, that the capacity of pre-differentiated osteogenic ASC-MT to enhance trabecular bone quality was comparable to undifferentiated ASCs, despite them having already been induced along the osteogenic lineage. This would therefore imply that the transplanted ASCs may have mediated their effects through the stimulation of resident cells, rather than instigating new bone formation directly. This concept was further tested in vitro utilizing ASCs and BMSCs isolated from human osteoporotic patients. Initial observations confirmed that the osteogenic potential of osteoporotic patient-derived BMSCs was significantly impaired as compared to normal, age-matched non-osteoporotic control samples. Furthermore, we could demonstrate that conditioned media harvested from osteoporotic patient-derived ASCs was able to better support osteoporotic patient-derived BMSC osteogenesis. Although similar findings were reported in studies utilizing human ASCs with either human BMSCs or mouse osteoblastic cell lines [21,39], as far as we are aware, this is the first direct evidence that human osteoporotic ASCs have the capacity to impart a pro-osteogenic paracrine effect on human osteoporotic patientderived BMSCs in vitro. It is possible therefore, that the increases in SAMP6 trabecular bone quality following ASC treatment were due, in part, to the paracrine actions of injected ASCs on resident BMSC populations.

\section{Conclusion}

We have demonstrated that ASCs isolated from osteoporotic SAMP6 mice have the capacity to undergo osteogenic differentiation and induce mineralized tissue formation in short- and longterm 3-D cultures, and that a single intratibial injection of undifferentiated ASCs or pre-differentiated ASC-MT, significantly enhanced parameters of bone quality in SAMP6 mice. Furthermore, in vitro data utilizing human osteoporotic patient-derived BMSCs and ASCs is provided, which supports the concept of transplanted ASCs influencing bone formation in a paracrine manner. Our data therefore highlights the potential benefits of using ASCs as an autologous cell-based therapeutic strategy to treat osteoporosis.

\section{Acknowledgements}

The authors would like to acknowledge Dr. Matthias Arlt (Balgrist University Hospital, University of Zurich), Dr. med. vet. Katja Nuss (Clinics for Horses, University of Zurich), and Dr. med. vet. Paula Grest (Institute for Veterinary Pathology, University of Zurich) for their assistance with the in vivo studies. This work has been partially financed with the help of the Forschungskredit University of Zurich and the Stiftung Osteoporose Schweiz.

\section{Appendix A. Supplementary data}

Supplementary data related to this article can be found online at http://dx.doi.org/10.1016/j.biomaterials.2014.05.016.

\section{References}

[1] Lane NE. Epidemiology, etiology and diagnosis of osteoporosis. Am J Obstet Gynecol 2006;194(Suppl. 2):S3-11.

[2] Rodríguez JP, Garat S, Gajardo H, Pino AM, Seitz G. Abnormal osteogenesis in osteoporotic patients is reflected by altered mesenchymal stem cells dynamics. J Cell Biochem 1999;75:414-23.

[3] Rodríguez JP, Montecinos L, Ríos S, Reyes P, Martínez J. Mesenchymal stem cells from osteoporotic patients produce a type I collagen-deficient extracellular matrix favoring adipogenic differentiation. J Cell Biochem 2000;79:557-65.

[4] Chen HT, Lee MJ, Chen CH, Chuang SC, Chang LF, Ho ML, et al. Proliferation and differentiation potential of human adipose-derived mesenchymal stem cells isolated from elderly patients with osteoporotic fractures. J Cell Mol Med 2012 Mar;16(3):582-93.

[5] Bonyadi M, Waldman SD, Liu D, Aubin JE, Grynpas MD, Stanford WL. Mesenchymal progenitor self-renewal deficiency leads to age-dependent osteoporosis in Sca-1/Ly-6A null mice. Proc Natl Acad Sci U S A 2003;100: $5840-5$.

[6] Kuro-o M, Matsumura Y, Aizawa H, Kawaguchi H, Suga T, Utsugi T, et al. Mutation of the mouse klotho gene leads to a syndrome resembling aging. Nature 1997;390:45-51.

[7] Jilka RL, Weinstein RS, Takahashi K, Parfitt AM, Manolagas SC. Linkage of decreased bone mass with impaired osteoblastogenesis in a murine model of accelerated senescence. J Clin Invest 1996;97:1732-40.

[8] Silva MJ, Brodt MD, Ko M, Abu-Amer Y. Impaired marrow osteogenesis is associated with reduced endocortical bone formation but does not impair periosteal bone formation in long bones of SAMP6 mice. J Bone Miner Res 2005;20:419-27.

[9] Egermann M, Heil P, Tami A, Ito K, Janicki P, Von Rechenberg B, et al. Influence of defective bone marrow osteogenesis on fracture repair in an experimental model of senile osteoporosis. J Orthop Res 2010;28:798-804.

[10] Astudillo P, Ríos S, Pastenes L, Pino AM, Rodríguez JP. Increased adipogenesis of osteoporotic human-mesenchymal stem cells (MSCs) characterizes by impaired leptin action. J Cell Biochem 2008 Mar 1;103:1054-65.

[11] Pino AM, Rosen CJ, Rodríguez JP. In osteoporosis, differentiation of mesenchymal stem cells (MSCs) improves bone marrow adipogenesis. Biol Res 2012;45:279-87.

[12] Rachner TD, Khosla S, Hofbauer LC. Osteoporosis: now and the future. Lancet 2011:377:1276-87.

[13] Seeman E, Delmas PD. Bone quality - the material and structural basis of bone strength and fragility. N Engl J Med 2006;354:2250-61.

[14] Tapp H, Hanley Jr EN, Patt JC, Gruber HE. Adipose-derived stem cells: characterization and current application in orthopaedic tissue repair. Exp Biol Med 2009;234:1-9.

[15] Antebi B, Pelled G, Gazit D. Stem cell therapy for osteoporosis. Curr Osteoporos Rep 2014;12:41-7.

[16] Schipper BM, Marra KG, Zhang W, Donnenberg AD, Rubin JP. Regional anatomic and age effects on cell function of human adipose-derived stem cells. Ann Plast Surg 2008;60:538-44.

[17] Zhu M, Kohan E, Bradley J, Hedrick M, Benhaim P, Zuk P. The effect of age on osteogenic, adipogenic and proliferative potential of female adipose-derived stem cells. J Tissue Eng Regen Med 2009;3:290-301.

[18] Khan WS, Adesida AB, Tew SR, Andrew JG, Hardingham TE. The epitope characterization and the osteogenic differentiation potential of human fat pad-derived stem cells is maintained with ageing in later life. Injury 2009;40: 150-7.

[19] Shi YY, Nacamuli RP, Salim A, Longaker MT. The osteogenic potential of adipose-derived mesenchymal cells is maintained with aging. Plast Reconstr Surg 2005;116:1686-96.

[20] Mirsaidi A, Kleinhans KN, Rimann M, Tiaden AN, Stauber M, Rudolph KL, et al. Telomere length, telomerase activity and osteogenic differentiation are maintained in adipose-derived stromal cells from senile osteoporotic SAMP6 mice. J Tissue Eng Regen Med 2012;6:378-90.

[21] Cho SW, Sun HJ, Yang JY, Jung JY, Choi HJ, An JH, et al. Human adipose tissuederived stromal cell therapy prevents bone loss in ovariectomized nude mouse. Tissue Eng Part A 2012;18:1067-78.

[22] You L, Pan L, Chen L, Chen JY, Zhang X, Lv Z, et al. Suppression of zinc finger protein 467 alleviates osteoporosis through promoting differentiation of adipose derived stem cells to osteoblasts. J Transl Med 2012;10:11.

[23] Liu HY, Chiou JF, Wu AT, Tsai CY, Leu JD, Ting LL, et al. The effect of diminished osteogenic signals on reduced osteoporosis recovery in aged mice and the potential therapeutic use of adipose-derived stem cells. Biomaterials 2012;33: 6105-12.

[24] Mirsaidi A, Tiaden AN, Richards PJ. Preparation and osteogenic differentiation of scaffold-free mouse adipose-derived stromal cell microtissue spheroids (ASC-MT). Curr Protoc Stem Cell Biol 27:2B.5.1-2B.5.12.

[25] Lindtner RA, Tiaden AN, Genelin K, Ebner HL, Manzl C, Klawitter M, et al. Osteoanabolic effect of alendronate and zoledronate on bone marrow stromal cells (BMSCs) isolated from aged female osteoporotic patients and its implications for their mode of action in the treatment of age-related bone loss. Osteoporos Int 2014;25:1151-61.

[26] Hofmann S, Hagenmüller H, Koch AM, Müller R, Vunjak-Novakovic G, Kaplan DL, et al. Control of in vitro tissue-engineered bone-like structures using human mesenchymal stem cells and porous silk scaffolds. Biomaterials 2007;28:1152-62.

[27] Thimm BW, Wüst S, Hofmann S, Hagenmüller H, Müller R. Initial cell precultivation can maximize ECM mineralization by human mesenchymal stem cells on silk fibroin scaffolds. Acta Biomater 2011;7:2218-28.

[28] Tiaden AN, Breiden M, Mirsaidi A, Weber FA, Bahrenberg G, Glanz S, et al. Human serine protease HTRA1 positively regulates osteogenesis of human bone marrow-derived mesenchymal stem cells and mineralization of differentiating bone-forming cells through the modification of extracellular matrix protein. Stem Cells 2012;30:2271-82. 
[29] Kohler T, Stauber M, Donahue LR, Muller R. Automated compartmental analysis for high-throughput skeletal phenotyping in femora of genetic mouse models. Bone 2007;41:659-67.

[30] Hildebrand T, Ruegsegger P. A new method for the model-independent assessment of thickness in three-dimensional images. J Microsc 1997;185:67-75.

[31] Hildebrand T, Laib A, Muller R, Dequeker J, Ruegsegger P. Direct threedimensional morphometric analysis of human cancellous bone: microstructural data from spine, femur, iliac crest, and calcaneus. J Bone Miner Res 1999; $14: 1167-74$.

[32] Helder MN, Knippenberg M, Klein-Nulend J, Wuisman PI. Stem cells from adipose tissue allow challenging new concepts for regenerative medicine. Tissue Eng 2007;13:1799-808.

[33] Dudas JR, Marra KG, Cooper GM, Penascino VM, Mooney MP, Jiang S, et al. The osteogenic potential of adipose-derived stem cells for the repair of rabbit calvarial defects. Ann Plast Surg 2006;56:543-8.

[34] Li H, Dai K, Tang T, Zhang X, Yan M, Lou J. Bone regeneration by implantation of adipose-derived stromal cells expressing BMP-2. Biochem Biophys Res Commun 2007;356:836-42.
[35] Yoon E, Dhar S, Chun DE, Gharibjanian NA, Evans GR. In vivo osteogenic potential of human adipose-derived stem cells/poly lactide-co-glycolic acid constructs for bone regeneration in a rat critical-sized calvarial defect model. Tissue Eng 2007;13:619-27.

[36] Liu Y, Zhou Y, Feng H, Ma GE, Ni Y. Injectable tissue-engineered bone composed of human adipose-derived stromal cells and platelet-rich plasma. Biomaterials 2008;29:3338-45.

[37] Zhou Y, Ni Y, Liu Y, Zeng B, Xu Y, Ge W. The role of simvastatin in the osteogenesis of injectable tissue-engineered bone based on human adiposederived stromal cells and platelet-rich plasma. Biomaterials 2010;31: $5325-35$.

[38] Guo L, Ge J, Zhou Y, Wang S, Zhao RC, Wu Y. Three-dimensional spheroidcultured mesenchymal stem cells devoid of embolism attenuate brain stroke injury after intra-arterial injection. Stem Cells Dev 2014;23: 978-89.

[39] Kim KI, Park S, Im GI. Osteogenic differentiation and angiogenesis with cocultured adipose-derived stromal cells and bone marrow stromal cells. Biomaterials 2014;35:4792-804. 